\title{
Meat quality of weaner steers adapted to a diet containing potassium humate in the feedlot
}

\author{
N. P. Mokotedi ${ }^{1,2,3}$, K. J. Leeuw ${ }^{3}$, U. Marume ${ }^{1,2 \#}$ \& A. Hugo ${ }^{4}$ \\ ${ }^{1}$ Department of Animal Science, Faculty of Agriculture, Science and Technology, North-West University, P. Bag X2046, \\ Mmabatho 2735, South Africa \\ ${ }^{2}$ Food Security and Safety Niche Area, Faculty of Agriculture, Science and Technology, North-West University, \\ Mmabatho, Mafikeng 2735, South Africa \\ ${ }^{3}$ Animal Production Institute, Agricultural Research Council, Private Bag X2, Irene, 0062, South Africa \\ ${ }^{4}$ Department of Microbial, Biochemical and Food Biotechnology, University of Free State, P.O. Box 339 Bloemfontein, \\ 9300, South Africa
}

(Received 14 August 2017; Accepted 10 October 2017; First published online 3 November 2017)

\begin{abstract}
Copyright resides with the authors in terms of the Creative Commons Attribution 4.0 South African Licence.
See: http://creativecommons.org/licenses/by/4.0/za

Condition of use: The user may copy, distribute, transmit and adapt the work, but must recognise the authors and the South African Journal of Animal Science.
\end{abstract}

\begin{abstract}
The objective of the study was to determine the meat quality responses of weaner steers fed diets containing potassium humate $(\mathrm{PH})$ in a feedlot. Twenty-two yearling male steers were randomly allocated to two treatments: control $(n=11)$, fed a standard feedlot diet and PH $(n=11)$, fed a standard diet with added $\mathrm{PH}(5.8 \mathrm{~g} / \mathrm{kg}$ feed). The steers were housed in individual stanchions, with each steer as the experimental unit. At the end of the feeding trial at Day 112, the steers were slaughtered and the m. longissimus thoracic et lumborum muscle was sampled for meat quality measurements. Results of the study showed that diet had no effect on carcass characteristics and meat quality measurements, apart from meat $\mathrm{pH}$ and shear force values. Meat $\mathrm{pH}$ decline was more pronounced in the control group and higher shear force values were observed in the control group (6.58 and $4.91 \mathrm{~kg}$ ) than the PH group (5.12 and $4.14 \mathrm{~kg}$ ) at Day 1 and Day 7 of measurement respectively. The total intramuscular fat (IMF) was higher (by 16\%) in the $\mathrm{PH}$ - fed weaner steers compared with the control. With regard to saturated fatty acids (SFA), higher amounts of myristic acid and heneicosanoic acid were observed in the $\mathrm{PH}$-fed steers than in the control. However, the control had higher amounts of eicosatrienoic acid and eicosatetraenoic acid. PH inclusion in steer diets could therefore provide an alternative growth promotant in the production of safe and healthier meat in the feedlot.
\end{abstract}

Keywords: Carcass characteristics, fatty acids, nutritional indices, shear force

\# Corresponding author: upenyu.marume@nwu.ac.za

\section{Introduction}

Growth promotants and feed additives have been used successfully to increase the rate of weight gain and improve feed efficiency in steers fed in confinement for slaughter. Globally, there is demand for meat, resulting in significant pressure on producers to meet consumer demands, which has made the use of commercial antibiotics and growth promotants inevitable. Antibiotics and growth promotants have the effects of significantly improving animal health, feed utilization efficiency, and growth performance. Although the use of commercial antibiotics and growth promotants in cattle feedlots is regulated based on allowable incremental levels, the continuous use of these drugs is causing anxiety among consumers owing to fears of increasing residues in meat and meat products (Callaway et al., 2003; APUA, 1999) that may affect their health. These ever-increasing concerns over the use of commercial growth promotants have provoked a need to explore natural alternatives as replacements for or modulators of current conventional growth promotants.

One of the natural growth promotants that is increasingly gaining interest is potassium humate $(\mathrm{PH})$ (Peña-Méndez et al., 2005). Studies that have been conducted on PH and similar compounds have brought new awareness of their structure and physicochemical properties, which gave birth to the idea of the use of these natural compounds in animal nutrition (McMurphy et al., 2009; Peña-Méndez et al., 2005; Kocabagli et 
al., 2002). Potassium humate is defined as a humic acid salt, which is derived mostly from lignite or peat (Chen et al., 2007; Stevenson \& Cole, 1999). Humate is a functional group containing a large number of complex organic macromolecular compounds (Chen et al., 2007). It is a non-toxic tasteless black/brown natural organic powder, which is soluble in water. Salts of humic acids are usually available as sodium humate or PH (Anon, 2009).

Information about the use of $\mathrm{PH}$ shows that it has growth-promoting effects in farm animals (Ragaa \& Korany, 2016; Dehghani-Taftia \& Jahaniana, 2016; Wang et al., 2008; Kocabagli et al., 2002). In addition, fulvic acids in humates have been shown to have beneficial effects on animal health by boosting the immune system as a result of their antipyretic, antiviral and detoxifying effects on toxic substances (Agazzi et al., 2007; Islam et al., 2005). Moreover, humates have been observed to reduce the volatile ammonia in animal waste (Islam et al., 2005). Islam et al. (2005) reported that humates can help relieve stress effects in calves entering feedlots for the first time. Although studies have been conducted on the use of $\mathrm{PH}$ as a growth promotant in animal feeding systems, many questions need to be answered. Most of these studies have focused on monogastric animals. There appears to be no conclusive information on the beneficial effects of $\mathrm{PH}$ on feedlot steers. Moreover, its effects on meat quality have not been elucidated. Therefore, the objective of this study was to establish the efficacy of $\mathrm{PH}$ as a growth promotant in feedlot diets, by assessing its effect on carcass characteristics and meat quality attributes of weaner calves in a feedlot.

\section{Materials and Methods}

The study was conducted in a cattle feedlot at the Animal Production Institute of the Agricultural Research Council (ARC-API) at Irene (longitude 2813 S, latitude 25055 E, altitude 1524m), located in the province of Gauteng in South Africa. The area is characterized by an ambient temperature of 18 to $29{ }^{\circ} \mathrm{C}$ in summer and between 5 and $20^{\circ} \mathrm{C}$ in winter.

Twenty-two yearling male steers (average weight $249.4 \pm 5.62$ ), weaned at $6-7$ months were randomly allocated to two treatments: Control $(n=11)$ was fed a standard mixed feedlot diet and $\mathrm{PH}(\mathrm{n}=11)$ was fed a standard diet with added $\mathrm{PH}(5.8 \mathrm{~g} / \mathrm{kg}$ feed). The animals were housed individually, with each animal as the experimental unit. PH inclusion was aimed to ensure an intake of $15 \mathrm{~g} / \mathrm{animal}$ per day. The steers were allowed to adapt to their environment for six days in which the single stanchions were left open for the animals to access water and hay. They were then allowed an adaptation period of 14 days for experimental diets before the start of growth performance measurements. All steers had free access to water. Daily feed allocations were changed according to the amount of orts in the feed troughs. Orts were removed weekly or as dictated by feed trough conditions and noted. Daily feed allocation was based initially on an estimated intake of $4 \mathrm{~kg} / \mathrm{day}$ for the first batch of feed. The second batch was mixed according to feed intake by the treatment group. Feed analysis for chemical composition was done according to the official methods for analytical chemistry (AOAC, 2005). The ingredients and nutritional composition of the starter and grower feeds are shown in Table 1.

The animals were raised and kept according to standard feedlot practices. Before the beginning of the experiment, the animals were ear-tagged for identification and vaccinated against internal parasites with Gardal $10 \%$ and against external parasites with Delete All $\AA$, and treated against possible bacterial and viral infectious diseases (Clostridium ssp., anthrax, botulism, Infectious Bovine Rhinotracheitis) with Ivotan, Covexin, Botu-thrax and Bovitech III. The steers were then placed in individual pens and fed an adaptation ration for 14 days. The pens $\left(2 \mathrm{~m}^{2}\right.$ per animal) were developed to meet the welfare standards as guided by the National Society for the Prevention of Cruelty to Animals (NSPCA, South Africa). The trial was carried over 112 days. Ethical clearance for the study was obtained from the ARC-API Ethics Committee (ethics clearance no. APIEC15/013).

At the end of the experiment at day 112, the animals were transported by light duty vehicle to the Meat Industry Centre (MIC) abattoir for slaughter to determine carcass weights and grading (based on age, fat code and confirmation score) (Leeuw et al, 2009). Before slaughter, steers were subjected to 12 hours fasting to empty their stomachs. Afterwards they were weighed to determine live weight at slaughter (LWS). At MIC, the steers were stunned electrically with a captive bolt, exsanguinated and eviscerated. After the head, skin, limbs and viscera had been removed, the remaining carcasses were electrically stimulated, using a voltage of $300 \mathrm{~V}$, a frequency of $50 \mathrm{~Hz}$, and a current of $5 \mathrm{~A}$ in $40-45$ seconds at a pulse of $12 / \mathrm{s}$. The carcasses were sawn through the centre of the vertebral column into right and left sides and weighed to obtain hot carcass weight $(\mathrm{HCW})$. The carcasses were then chilled overnight for 24 hours at $4{ }^{\circ} \mathrm{C}$, then weighed to obtain the cold carcass weight (Lopez et al., 2012). Dressing percentage was calculated as warm carcass weight expressed as a proportion of final live weight. Fat scores were evaluated using a scale of 0 6 , in which $0=$ no fat, and 6 = excessive fat (Mantiziba, 2014). The m. longissimus thoracis et lumborum (LTL) of the left side was sampled a day after slaughter from the 10th rib in the direction of the rump for meat quality analysis. 
Table 1 Feed ingredients $(\mathrm{kg})$ and estimated nutrient composition $(\% / \mathrm{kg}$ dry matter) of the Control diet and treatment diet containing $\mathrm{PH}$

\begin{tabular}{lcc}
\hline Feed Ingredient & Control $\mathbf{( k g )}$ & PH $\mathbf{~ k g})$ \\
\hline Hominy chop & 615 & 615 \\
Wheat bran & 150 & 150 \\
Molasses meal & 100 & 100 \\
Cotton OCM & 50 & 50 \\
Grass hay & 50 & 50 \\
Feed lime & 15 & 15 \\
Urea & 14 & 14 \\
Salt & 5 & 5 \\
Premix & 1 & 1 \\
Potassium humate & 0 & $5.8 \mathrm{~g} / \mathrm{kg}$ \\
Nutritional composition & & \\
ME (MJ/kg DM) & 11.83 & 12.05 \\
Fat (\%) & 5.69 & 5.95 \\
CP (\%) & 15.21 & 16.15 \\
CF (\%) & 13.4 & 12.9 \\
NDF (\%) & 31.2 & 24.1 \\
Ca (\%) & 0.68 & 0.77 \\
P (\%) & 0.59 & 0.63 \\
K (\%) & 1.12 & 1.21
\end{tabular}

'Oilcake meal, extracted; CP: crude protein, CF: crude fibre, NDF: neutral detergent fibre, Ca: calcium, P: phosphorus, $\mathrm{K}$ : potassium. ME: metabolizable energy

The $\mathrm{pH}$ and temperature values of the $\mathrm{LTL}$ were measured with a digital hand-held meat $\mathrm{pH}$ meter (Crison $\mathrm{pH}$ 25, Crison Instruments, S.A., Alella, Spain) at 1, 2, 3 and 24 hours after slaughter. For drip loss measurement, two blocks of meat measuring $15 \times 15 \times 30 \mathrm{~mm}$ were sliced from the LTL steak so that the fibres ran across the longer axis of the sample. The samples were suspended on metal hooks in plastic sample bottles so that the sample did not touch the side of the bottle. The samples were stored in a cold room at $2{ }^{\circ} \mathrm{C}$ for 72 hours. Drip loss was calculated as the difference between the initial and final weights of the sample, expressed as a percentage.

Muscle colour was measured with a Minolta meter (model CR200, Minolta, Japan) on fresh samples (two days post mortem). The Minolta meter was calibrated before measurements with a white tile for standard white colour calibration. A $30 \mathrm{~g}$ portion of the LTL was cut and left to flourish for at least 30 min at chilled temperatures $\left(3^{\circ} \mathrm{C}\right)$ before recording. The following colour coordinates were measured: lightness $\left(\mathrm{L}^{*}\right)$, redness $\left(a^{*}\right)$ and yellowness $\left(b^{*}\right)$ from three locations on the cut surface of individual steaks. Three replicate measurements, which avoided areas of connective tissue and intramuscular fat, were taken per sample.

Meat tenderness (shear force measurements) was determined with Instron 3344 universal testing cross head speed at $400 \mathrm{~mm} / \mathrm{min}$, one shear in the centre of each core). Following cooking, sub samples of specified core diameter were cored parallel to the grain of the meat. The samples were sheared perpendicular to the fibre direction using a Warner Bratzler (WB) shear device mounted on an Instron 3344 (universal testing) and mean maximum load $(\mathrm{N})$ was recorded for each sample. Warner-Bratzler Shear Force (WBSF) values and cooking loss were determined on day 1 after slaughter and day 7 of ageing. Cooking loss was determined as weight of drip after cooking expressed as a percentage.

Total lipid from muscle samples was extracted quantitatively, according to the method of Folch et al. (1957), using chloroform and methanol in a ratio of 2:1. The antioxidant butylated hydroxytoluene was added at a concentration of $0.001 \%$ to the chloroform/methanol mixture. A rotary evaporator was used to dry the fat extracts under vacuum, and the extracts were dried overnight in a vacuum oven at $50^{\circ} \mathrm{C}$, using phosphorus pentoxide as a moisture adsorbent. Total extractable intramuscular fat was determined gravimetrically from the extracted fat and expressed as percentage fat (w/w) per $100 \mathrm{~g}$ tissue. The fat-free dry matter (FFDM) 
content was determined by weighing the residue on a pre-weighed filter paper, used for Folch extraction, after drying. By determining the difference in weight, the FFDM could be expressed as percentage FFDM $(\mathrm{w} / \mathrm{w})$ per $100 \mathrm{~g}$ tissue. The extracted fat was stored in a polytop (glass vial with push-in top) under a blanket of nitrogen and frozen at $-20^{\circ} \mathrm{C}$, pending fatty acid analyses.

A lipid aliquot ( $\pm 30 \mathrm{mg}$ ) of muscle lipid was converted to methyl esters by base-catalysed transesterification to avoid conjugated linoleic acid isomerization, with sodium methoxide $(0.5 \mathrm{M}$ solution in anhydrous methanol) in 2 hours at $30^{\circ} \mathrm{C}$, as proposed by Park et al. (2001), Kramer et al. (2002) and Alfaia et al. (2007). Fatty acid methyl esters (FAMEs) from feed, muscle and subcutaneous fat were quantified with a Varian 430 flame ionization GC, with a fused silica capillary column, Chrompack CPSIL 88 (100 m length, $0.25 \mathrm{~mm} \mathrm{ID}, 0.2 \mu \mathrm{m}$ film thicknesses). Analysis was performed with an initial isothermic period $\left(40^{\circ} \mathrm{C}\right.$ for 2 minutes). Then, temperature was increased at a rate of $4{ }^{\circ} \mathrm{C} /$ minute to $230{ }^{\circ} \mathrm{C}$. Finally, an isothermic period of $230{ }^{\circ} \mathrm{C}$ for 10 minutes followed. FAMEs n-hexane $(1 \mu \mathrm{l})$ was injected into the column using a Varian $\mathrm{CP}$ 8400 auto sampler. The injection port and detector were maintained at $250{ }^{\circ} \mathrm{C}$. Hydrogen, at 45 psi, functioned as the carrier gas, while nitrogen was employed as the makeup gas. A galaxy chromatography data system software recorded the chromatograms.

FAME samples were identified by comparing the retention times of FAME peaks from samples with those of standards obtained from Supelco (Supelco 37 Component Fame Mix 47885-U, Sigma-Aldrich Aston Manor, Pretoria, South Africa). CLA standards were obtained from Matreya Inc. (Pleasant Gap, United States). These standards included cis-9, trans-11 and trans-10, cis-12-18:2 isomers. Nonadecanoic acid (C19:0) (SIGMA N553377-1G) was used as the internal standard to improve quantitative FAME estimation. Fatty acids were expressed as the proportion of each fatty acid to the total of fatty acids present in the sample. Fatty acid data were used to calculate these ratios of FAs, namely total SFAs; total monounsaturated fatty acids (MUFAs); total polyunsaturated fatty acids (PUFAs); PUFA/SFA; $\Delta^{9}$ desaturase index (C18:1c9/C18:0); total omega-6; total omega-3; the ratio of omega-6 to omega-3 (n-6)/( $n-3)$ FAs. Atherogenicity indices were computed as the ratio of SFA/ unsaturated FA using the formula proposed by Chilliard et al. (2003):

Atherogenicity index $(\mathrm{AI})=[\mathrm{C} 12: 0+4(\mathrm{C} 14: 0)+(\mathrm{C} 16: 0)] / \sum(\mathrm{MUFA}+\mathrm{PUFA})$

The $\Delta^{9}$ desaturase indices were computed using the following ratios:

Desaturase index (DI) $=$ C18: $1 \mathrm{c} 9 / \mathrm{C} 18: 0$

Desaturase activity $(\mathrm{DA})=\left(\sum \Delta 9\right.$ desaturase products $) /\left(\sum \Delta 9\right.$ desaturase substrates + products $)$

(3)

The desaturase indices were used as an indicator of the $\Delta^{9}$ desaturase activity using fatty acids that are substrates and products for $\Delta^{9}$ desaturase.

Lipid peroxidation was determined by the method described by Alam et al. (2013), which involved thiobarbituric acid reactive species (TBARS) with malondialdehyde (MDA) as standard (Merck Chemicals (Pty) Ltd, Halfway House, Johannesburg, South Africa). A volume of $0.1 \mathrm{~mL}$ meat supernatant was treated with $2 \mathrm{~mL}(1: 1: 1$ ratio) TBA-TCA-HCl reagent (thiobarbituric acid $0.37 \%, 15 \%$ trichloroacetic acid and $0.25 \mathrm{~N} \mathrm{HCl}$ ). All tubes were placed in a boiling water bath for 30 minutes and allowed to cool. The amount formed in each of the samples was assessed by measuring the optical density of the supernatant at $535 \mathrm{~nm}$ using a spectrophotometer (Hewlett Packard, UV/visible light) against a reagent blank. Percentage inhibition was calculated using the equation:

$$
\% \text { of lipid oxidation inhibition }=\{\text { Ao- } A 1\} / A o \times 100
$$

Where: $A 0=$ the absorbance of the control and $A 1=$ the absorbance of the sample extract.

Data for meat quality responses to the inclusion of $\mathrm{PH}$ in diets was analysed using general linear models of SAS (2008) for the analysis of variance, with diet as the fixed factor. The Shapiro-Wilk test was used to test the data for normality. Comparisons of means between the control and PH group were assessed using independent $\mathrm{t}$-tests for pairwise comparisons.

\section{Results and Discussion}

The current study is one of the few attempts that have been made with regard to the use of nonconventional growth promotants in beef with the objective of producing meat with reduced residues that is acceptable to the consumers. From the results, diet had no effect on any of the carcass measurements, although the control had marginally higher values for carcass measurements than PH-fed steers (Table 2). This indicates that inclusion of $\mathrm{PH}$ in the diets of steers could result in similar effects of carcass 
characteristics to conventional growth promotants. Moreover, no differences were observed in the objective meat quality parameters measured in the study, except for shear force values and meat $\mathrm{pH}$. The comparable values of carcass and meat quality parameters may be a reflection of similar treatments of animals prior to slaughter, as observed in other studies (Coleman et al., 2016, Mapiye et al., 2010).

Table 2 Mean $( \pm$ SE) meat quality characteristics of weaner steers

\begin{tabular}{|c|c|c|c|}
\hline \multirow{2}{*}{ Parameter } & \multicolumn{3}{|c|}{ Treatments } \\
\hline & Control & $\mathbf{P H}$ & Sig \\
\hline \multicolumn{4}{|l|}{ Carcass measurements } \\
\hline Slaughter weight (kg) & $477.9 \pm 9.45$ & $428.4 \pm 9.01$ & NS \\
\hline HCW (right side) kg & $133.3 \pm 2.99$ & $128.1 \pm 2.86$ & NS \\
\hline HCW (left side) kg & $132.5 \pm 3.33$ & $126.2 \pm 3.17$ & NS \\
\hline CCW (right side) $(\mathrm{kg})$ & $130.2 \pm 3.05$ & $125.1 \pm 2.91$ & NS \\
\hline CCW (left side) (kg) & $129.4 \pm 3.2$ & $123.9 \pm 3.05$ & NS \\
\hline Dressing out $\%$ & $57.9 \pm 0.53$ & $58.1 \pm 0.51$ & NS \\
\hline Eye muscle area $\left(\mathrm{mm}^{2}\right)$ & $7849.3 \pm 276.9$ & $7747 \pm 263.9$ & NS \\
\hline Fat score (corrected) & $3.70 \pm 0.65$ & $3.18 \pm 0.63$ & NS \\
\hline Carcass conformation & $3.30 \pm 0.16$ & $3.09 \pm 0.15$ & NS \\
\hline Cooking loss (Day 1) (\%) & $27.7 \pm 4.44$ & $26.9 \pm 3.34$ & NS \\
\hline Cooking loss (Day 7) (\%) & $26.7 \pm 2.77$ & $26.6 \pm 3.46$ & NS \\
\hline Drip loss (Day 1) (\%) & $5.4 \pm 1.9$ & $5.18 \pm 1.06$ & NS \\
\hline Drip loss (Day 7) (\%) & $5.24 \pm 1.25$ & $4.78 \pm 1.25$ & NS \\
\hline Shear force (Day 1) (kg) & $6.58 \pm 1.23$ & $5.12 \pm 0.86$ & * \\
\hline Shear force (Day 7) (kg) & $4.91 \pm 1.04$ & $4.14 \pm 0.74$ & * \\
\hline Meat colour & & & NS \\
\hline$L^{*} 1 h$ & $34.4 \pm 0.75$ & $36.6 \pm 0.72$ & NS \\
\hline$a^{*} 1 h$ & $17.5 \pm 1.08$ & $17.1 \pm 1.02$ & NS \\
\hline$b^{*} 1 h$ & $15.2 \pm 0.53$ & $14.7 \pm 0.51$ & NS \\
\hline$C * 1 h$ & $23.4 \pm 1.04$ & $22.7 \pm 0.99$ & NS \\
\hline $\mathrm{H} 1 \mathrm{~h}$ & $41.6 \pm 1.57$ & $41.7 \pm 1.50$ & NS \\
\hline$L^{*} 24$ & $42.3 \pm 0.62$ & $41.2 \pm 0.62$ & NS \\
\hline$a^{*} 24$ & $15.4 \pm 0.93$ & $15.2 \pm 0.86$ & NS \\
\hline$b^{\star} 24$ & $6.42 \pm 0.55$ & $5.73 \pm 0.51$ & NS \\
\hline$C * 24$ & $16.8 \pm 0.99$ & $16.4 \pm 0.94$ & NS \\
\hline $\mathrm{H} 24$ & $22.2 \pm 1.27$ & $20.1 \pm 1.22$ & NS \\
\hline
\end{tabular}

*Significant at $P<0.05$; NS: not significant; HCW: hot carcass weight; CCW: cold carcass weight; $L^{*}$ : lightness; $\mathrm{a}^{*}$ : redness; $b^{*}$ : yellowness; $\mathrm{C}^{*}$ : chroma; $\mathrm{H}$ : hue

Meat tenderness is one of the critical indicators of meat quality that may have a significant effect on its eating quality. Factors such as ultimate $\mathrm{pH}$, intramuscular fat, and extent of proteolytic activities in meat have significant influences on the level of tenderness of meat (Coleman et al., 2016; Muchenje et al., 2009). In the current study, shear force was significantly $(P<0.05)$ affected by diet, with higher values observed in the control than the PH group on Day 1 and Day 7 of measurement, respectively. The observed significant effect of diet on shear force on Day 1 and Day 7 of ageing is contrary to the findings from previous reports (Mapiye et al., 2010; French et al., 2001). The lower shear force values in the PH-fed steers could be ascribed to the effects of $\mathrm{PH}$ in modulating energy and protein digestion dynamics during the growth phase (Wang et al., 
2008; Kocabagli et al., 2002) and proteolytic activities during the rigor phase and the seven-day ageing period (Jung et al., 2010). Nevertheless, this needs further verification.

The $\mathrm{pH}$ of meat is regarded as the measure of acidity, and the ultimate $\mathrm{pH}$ is determined by the extent of $\mathrm{pH}$ decline 24 hours after slaughter (Muchenje et al., 2009). In the current study, the post-mortem decline in $\mathrm{pH}$ was steeper $(P<0.05)$ in the control, although ultimately the $\mathrm{PH}$ group had a lower $(P<0.05)$ ultimate $\mathrm{pH}\left(\mathrm{pH}_{24}\right)$ than the control (Figure 1). The ultimate $\mathrm{pH}$ in the two treatment groups, however, was on the lower end of the recommended pH of a good quality meat, which is usually from 5.4 to 5.7 (Kerry \& Ledward, 2009). Although there was no apparent variation the two treatments, it has generally been concluded that the rates of muscle $\mathrm{pH}$ and temperature decline and the $\mathrm{pH}$-temperature interaction during the immediate postmortem period may have a significant effect on meat tenderness (Xazela et al., 2012; Kannan et al., 2006).

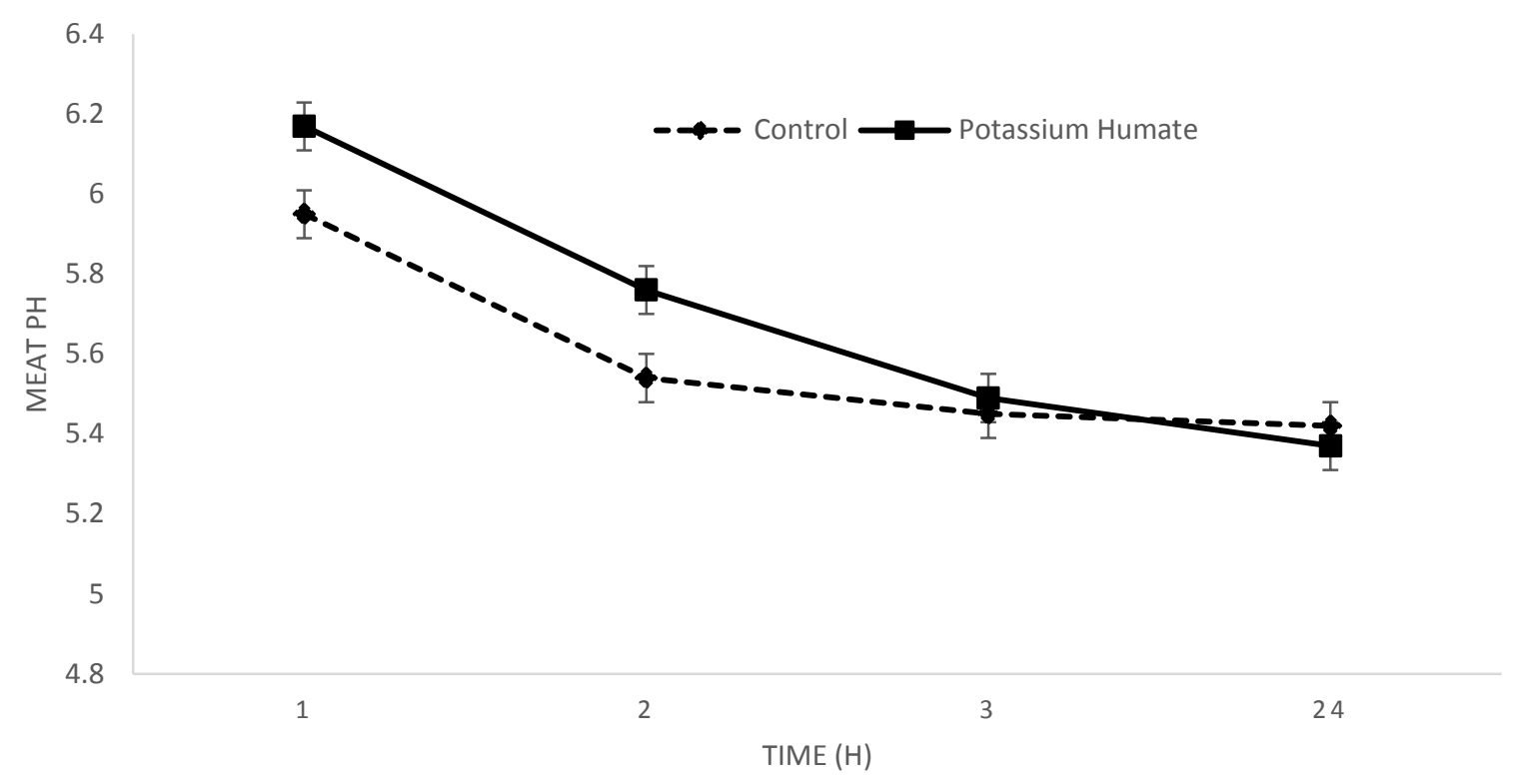

Figure $1 \mathrm{Effect}$ of $\mathrm{PH}$ inclusion on post-mortem decline in meat $\mathrm{pH}$ of weaner steers

The fatty acid composition of meat is one of the critical determinants of the nutritional value of meat (Coleman et al., 2016; Vessby et al., 2013). A low proportion of PUFAs and a high proportion of SFAs in meat may increase the risk of cardiovascular disease (Mapiye et al., 2011; Wood et al., 2004). In the current study, the total IMF was higher (by $16 \%, P<0.05$ ) in the $\mathrm{PH}$-fed weaner steers compared with the control (Table 3). With regard to SFAs, higher $(P<0.05)$ amounts of myristic acid $(C 14: 0)$ and heneicosanoic acid (C21:0) were observed in the PH-fed steers compared with control. However, diet had no effect on any of the other SFAs. Similarly, diet had no effect on MUFAs. On the contrary, diet affected PUFAs, with the control having more $(P<0.05)$ eicosatrienoic acid $[(\mathrm{C} 20: 3 \mathrm{c} 8,11,14(\mathrm{n}-6)]$ and eicosatetraenoic acid $(\mathrm{C} 20: 4 \mathrm{c} 5,8$, $11,14(n-6))$. With regard to nutritional indices, only the PUFA : MUFA ratio was affected, with the control having a higher $(P<0.05)$ ratio compared with the $\mathrm{PH}$ group. No other indices were affected by diet. Diet had no effect on atherogenicity and desaturase indices. The ratios of $\mathrm{C} 14: 0 / \mathrm{C} 14: 1$ did not differ significantly between the muscles of steers receiving PH or control diets. Similarly, TBARS values were similar between the two treatments. 
Table 3 Mean ( \pm SE) fatty acid composition (\%) of $L$. dorsi muscle from weaner steers

\begin{tabular}{|c|c|c|c|c|}
\hline \multirow{2}{*}{ Fatty acids } & \multicolumn{4}{|c|}{ Treatments } \\
\hline & Control & PH & SEM & Sig \\
\hline \multicolumn{5}{|l|}{ Proximate fat composition } \\
\hline IMF & 1.66 & 1.97 & 0.09 & * \\
\hline FFDM & 22.07 & 22.04 & 0.24 & NS \\
\hline Moisture & 76.27 & 76 & 0.27 & NS \\
\hline \multicolumn{5}{|l|}{ Individual fatty acids } \\
\hline C12:0 & 0.004 & 0.02 & 0.01 & NS \\
\hline C14:0 & 2.47 & 3.03 & 0.17 & * \\
\hline C15:0 & 0.32 & 0.34 & 0.02 & NS \\
\hline $\mathrm{C} 16: 0$ & 26.11 & 27.01 & 0.6 & NS \\
\hline C17:0 & 1.76 & 1.6 & 0.07 & NS \\
\hline C18:0 & 16.58 & 16.94 & 0.49 & NS \\
\hline C20:0 & 0.06 & 0.07 & 0.01 & NS \\
\hline C21:0 & 0.29 & 0.23 & 0.01 & * \\
\hline C23:0 & 3 & 2.35 & 0.27 & NS \\
\hline C14:1c9 & 0.34 & 0.45 & 0.05 & NS \\
\hline C16:1c9 & 2.07 & 2.32 & 0.14 & NS \\
\hline C17:1c10 & 0.33 & 0.45 & 0.06 & NS \\
\hline C18:1t9 & 0.25 & 0.18 & 0.08 & NS \\
\hline C18:1c9 & 31.38 & 31.93 & 0.87 & NS \\
\hline C18:1c7 & 3.43 & 3.52 & 0.3 & NS \\
\hline C18:2c9,t11 (n-6) & 0.2 & 0.21 & 0.02 & NS \\
\hline C18:2c9,12 (n-6) & 9.26 & 7.60 & 0.74 & NS \\
\hline C18:3c6,9,12(n-3) & 0.01 & 0.02 & 0.01 & NS \\
\hline C18:3c9,12, 15 (n-3) & 0.42 & 0.4 & 0.02 & NS \\
\hline $\mathrm{C} 20: 2 \mathrm{c} 11,14(\mathrm{n}-6)$ & 0.02 & 0.02 & 0.01 & NS \\
\hline $\mathrm{C} 20: 3 \mathrm{c} 8,11,14(\mathrm{n}-6)$ & 0.06 & 0.04 & 0.01 & * \\
\hline $\mathrm{C} 20: 4 \mathrm{c} 5,8,11,14(\mathrm{n}-6)$ & 0.5 & 0.37 & 0.04 & * \\
\hline $\mathrm{C} 20: 5 \mathrm{c} 5,8,11,14,17(\mathrm{n}-3)$ & 0.01 & 0.01 & 0.02 & NS \\
\hline $\mathrm{C} 22: 5 \mathrm{c} 7,10,13,16,19(\mathrm{n}-3)$ & 0.42 & 0.35 & 0.04 & NS \\
\hline \multicolumn{5}{|l|}{ Nutritional indices } \\
\hline Total SFA & 47.6 & 49.3 & 0.82 & NS \\
\hline Total MUFA & 38.3 & 39.2 & 1.15 & NS \\
\hline Total PUFA & 14.1 & 11.5 & 1.11 & NS \\
\hline Total n-6 & 12.5 & 10.2 & 1.01 & NS \\
\hline Total n-3 & 1.56 & 1.29 & 0.11 & NS \\
\hline PUFA : SFA & 0.26 & 0.21 & 0.02 & NS \\
\hline PUFA : MUFA & 0.3 & 0.23 & 0.02 & * \\
\hline$n-6: n-3$ & 8.05 & 7.86 & 0.3 & NS \\
\hline Atherogenicity index & 0.55 & 0.6 & 0.02 & NS \\
\hline Desaturase index & 1.92 & 1.89 & 0.09 & NS \\
\hline TBARS & 0.04 & 0.04 & 0.01 & NS \\
\hline
\end{tabular}


Generally, the PUFA to SFA ratio and omega- 6 to omega- 3 ratio are indicators of the nutritional value of meat and the consumption of higher proportions of omega- 3 fatty acids is associated with reduced cardiovascular disease and cancer (Aldai et al., 2007; Simopoulos, 1999). In the current study, although there were no significant differences in the PUFA/SFA ratio and the n6/n3 ratio, the PUFA/SFA ratios for both treatments were well below the desired ratio of 0.45 . Nevertheless, the ratios obtained in the current study were higher than those obtained by Coleman et al. (2016). The observed low total omega-3 fatty acids in the current study could be because of the low amounts of C18:3 n-3 and C20:5 n-3 that normally characterize the total mixed rations that are given to the steers. This is consistent with observations from other studies (Vasta et al., 2009; Warren et al., 2008). Contrary to the findings by Warren et al. (2008), the $n 6: n 3$ ratio was well above the recommended values of $<5: 1$, pointing to the unbalanced levels of PUFAs in meat from both treatments. However, the ratios were lower than those reported for yearling steers of different genotypes by Aldai et al. (2007).

The nutritional value of meat is determined not only by the proportions of fatty acids in it, but also by the endogenous metabolism of the fatty acids, particularly $\Delta^{9}$ desaturase activity, atherogenicity and its oxidative stability (Vessby et al., 2013, Vasta et al., 2009). $\Delta^{9}$ desaturase (stearoyl-coenzyme-A desaturase 1 (SCD-1) activity plays a critical role in modulating the intracellular effects of SFA and the production of CLA and MUFA (Nantapo et al., 2014; Vessby et al., 2013; Souyert et al., 2006). In the current study, the lack of differences in desaturate index (DI) and atherogenicity index between the two treatment groups concurs with findings from other studies (Vasta et al., 2009). High values for DI and atherogenicity index of meat may be associated with increased risks of cardiovascular disease (Vessby et al., 2013). Interestingly, no difference in the TBARS was observed between the two treatments in the current study. Owing to the presence of phenolic compounds that have been observed to have antioxidative properties, $\mathrm{PH}$ was expected to increase the oxidative stability of the meat by significantly reducing the TBARS levels (Rababah et al., 2006). A possible explanation could be that the $\mathrm{PH}$ levels used in the diets were too low to cause significant reduction in lipid oxidation, hence the similarities observed between the treatments.

\section{Conclusion}

From the results, diet had no effect on carcass characteristics and meat quality measurement, apart from meat $\mathrm{pH}$ and shear force values. Higher shear force values were observed in the control group compared with the PH group. With regard to fatty acids, total IMF was increased by up to $16 \%$ in the PH-fed weaner steers compared with the control. However, the control group had higher amounts of PUFAs, including eicosatrienoic acid (C20:3c8, 11, $14(n-6))$ and eicosatetraenoic acid (C20:4c5, 8, 11, 14 (n6)). Therefore, $\mathrm{PH}$ inclusion in steer diets could provide an alternative to the conventional growth promotants in the production of safe and healthier meat in the feedlots, although more verification needs to be done to provide conclusive evidence.

\section{Acknowledgements}

The authors wish to thank Omnia Nutriology (Pvt, Ltd) for funding the research and ARC for providing the experimental housing and meat quality analysis.

\section{Authors' Contributions}

NPM participated in designing the study, laboratory analysis, and manuscript writing. KJL was involved in the design of the study data analysis and manuscript writing. UM was involved in the statistics and interpretation of the data and constructive revision of manuscript. AH participated in laboratory analysis, interpretation of the data and constructive revision of the manuscript.

\section{Conflict of Interest Declaration}

The authors declare that they have no competing interests

\section{References}

Agazzi, A., Cigalino, G., Mancin, G., Savoini, G., Dell'Orto, V., 2007. Effects of dietary humates on growth and an aspect of cell-mediated immune response in newborn kids. Small Rumin. Res. 72, 242-245.

Alam, N., Bristi, N.J. \& Rafiquzzaman, M., 2013. Review on in vivo and in vitro methods evaluation of antioxidant activity. Saudi Pharm. J. 21, 143-152.

Aldai, N., Nájera, A.I., Dugan, M.E.R., Celaya, R. \& Osoro, K., 2007. Characterization of intramuscular, intermuscular and subcutaneous adipose tissues in yearling bulls of different genetic groups. Meat Sci. 76, 682-691.

Alfaia, C.M.M, Castro, M.L.F., Martins, S.I.V., Portugal, A, P, V, Alves, S.P.A., Fontes, C.M.G.A., Bessa, R.J.B. \& Prates, J.A.M., 2007. Effect of slaughter season on fatty acid composition, conjugated linoleic acid isomers and nutritional value of intramuscular fat in Barrosã-PDO veal. Meat Sci. 75, 44-52

Anon, 2009. Humates for animal health. http://blog.nutri-tech.com.au/humates-for-animal-health/. Date of access 09 April 2015.

AOAC, 2005. Official methods of analytical chemistry. 17th edition. Maryland, USA. 
APUA (Alliance for the Prudent Use of Antibiotics), 1999. Facts about antibiotics in animals and their impact on resistance. 23 October 2002. Available at http: // www.tufts.edu/med/apua/Ecology/faair.html.

Callaway, T.R., Edrington, T.S., Rychlik, J.L., Genovese, K.J., Poole, J.L., Jung, Y.S., Bischoff, K.M., Anderson, C.R. \& Nisbet, J.D., 2003. Ionophores: Their use as ruminant growth promotants and impact on food safety. Curr. Issues Intest. Microbiol. 4, 43-51.

Chen, C., Wang, X., Jiang, H. \& Hu, W., 2007. Direct observation of macromolecular structures of humic acids by AFM and SEM. Colloids Surf. 302,121-125.

Chilliard, Y., Ferlay, A., Rouel, J. \& Lambere, G., 2003. A review of nutritional and physiological factors affecting goat milk synthesis and lipolysis. J. Dairy Sci. 86, 1751-1770

Coleman, L.W., Hickson, R.E., Schreurs, N.M., Martin, N.P., Kenyon, P.R., Lopez-Villalobos, N. \& Morris, S.T., 2016. Carcass characteristics and meat quality of Hereford sired steers born to beef-cross-dairy and Angus breeding cows. Meat Sci. 121, 403-408.

Dehghani-Taftia, N. \& Jahaniana, R., 2016. Effect of supplemental organic acids on performance, carcass characteristics, and serum biochemical metabolites in broilers fed diets containing different crude protein levels. Anim. Feed Sci. Technol. 211, 109-116.

Folch, J., Less, M. \& Stanley, G.H.S., 1957. A simple method for the isolation and purification of total lipid from animal tissues. J. Biol. Chem. 226, 499-509.

French, P., O'Riordan, E.G., Monahan, F.J., Caffrey, P.J., Mooney, M.T., Troy, D.J. \& Moloney, A.P., 2001. The eating quality of meat of steers fed grass and/or concentrates. Meat Sci. 57, 379-386.

Islam, K.M.S., Schuhmacher, A. \& Gropp, J.M., 2005. Humic acid substances in animal agriculture. Pakistan J. Nutr. 4 , 126-134.

Jung, S., Choe, J., Kim, B., Yun, H., Kruk, Z.A. \& Jo, C., 2010. Effect of dietary mixture gallic acid and linoleic acid on antioxidative potential and quality of breast meat from broilers. Meat Sci. 86, 520-526.

Kannan, G., Gadiyaram, K.M., Galipalli, S., Carmichael, A., Kouakou, B., Pringle, T.D., McMillin, K.W. \& Gelaye, S., 2006. Meat quality in goats as influenced by dietary protein and energy levels, and post-mortem aging. Small Rumin. Res. 61, 45-52.

Kerry, J.P. \& Ledward, D., 2009. Improving the sensory and nutritional quality of fresh meat. Wood, England.

Kocabagli, N., Alp, M., Acar, N. \& Kahraman, R., 2002.The effects of dietary humate supplementation on broiler growth and carcass yield. Poult. Sci. 81, 227-230.

Kramer, J.K., Blackadar, C.B. \& Zhou, J., 2002. Evaluation of two GC columns (60 m Supelcowax 10 and $100 \mathrm{~m}$ CP Sil 88) for analysis of milkfat with emphasis on CLA, 18:1, 18:2 and 18:3 isomers, and short and long-chain fatty acids. Lipids 37, 823-835.

Leeuw, K-J., Siebrits, F.K., Henning, P.H. \& Meissner, H.H., 2009. Effect of Megasphaera elsdenii NCIMB 41125 drenching on health and performance of steers fed high and low roughage diets in the feedlot. S. Afr. J. Anim. Sci. 39, 337-348.

Lopez, E.J., Peraza-Mercado, G., Holguiny, F.M. \& Ortiz, M.F.I., 2012. Relationship between live animal weight, warm and cold carcass weight and carcass principal components. Glob. Vet. 9, 179-183.

Mantiziba, C.P., 2014. The effect of zilpaterol hydrochloride on feedlot performance and carcass characteristics in weaner steers. MSc (Master of Science in Agriculture-Animal Science) thesis, University of South Africa.

Mapiye, C., Chimonyo, M., Dzama, K., Muchenje, V. \& Strydom, P.E., 2010. Meat quality of Nguni steers supplemented with Acacia karoo leaf-meal. Meat Sci. 84, 621-627.

Mapiye, C., Chimonyo, M., Dzama, K., Hugo, A., Strydom, P.E. \& Muchenje, V., 2011. Fatty acid composition of beef from Nguni steers supplemented with Acacia karroo leaf-meal. J. Food Comp. Ana. 24, 523-528.

McMurphy, C.P., Duff, G.C., Harris, M.A., Sanders, S.R., Chirase, N.K. \& Bailey, C.R., 2009. The effects of humic/fulvic acid in beef cattle finishing diets on animal performance, ruminal ammonia and serum urea nitrogen concentration. J. Appl. Anim. Res. 35, 97-100.

Muchenje, V., Dzama, K., Chimonyo, M., Strydom, P.E., Hugo, A. \& Raats, J.G., 2009. Some biochemical aspects pertaining to beef eating quality and consumer health: a review. Food Chem. 112, 279-289.

Nantapo, C.T.W., Muchenje, V. \& Hugo, A., 2014. Atherogenicity index and health-related fatty acids in different stages of lactation from Friesian, Jersey and Friesian $\times$ Jersey cross cow milk under a pasture-based dairy system. Food Chem. 146, 127-133.

Park, Y., Albright, K.J., Cai, Z.Y. \& Pariza, M.W., 2001. Comparison of methylation procedures for conjugated linoleic acid and artefact formation by commercial (trimethylsilyl) diazomethane. J. Agric. Food Chem. 49, 1158-1164.

Peña-Mèndez, E.M, Havel, J. \& Patočka, J., 2005. Review: Humic substances in compounds of still unknown structure: Applications in agriculture, industry, environment, and biomedicine. J. Appl. Biomed. 3, 13-24.

Rababah, T., Hettiarachchy, N.S., Horax, R., Cho, M.J., Davis, B. \& Dickson, J., 2006. Thiobarbituric acid reactive substances and volatile compounds in chicken breast meat infused with plant extracts and subjected to electron beam irradiation. Poult. Sci. 8, 1107-1113.

Ragaa, N.M. \& Korany, R. M.S., 2016. Studying the effect of formic acid and potassium diformate on performance, immunity and gut health of broiler chickens. Anim. Nutr. 2, 296-302.

Simopoulos, A. P., 1999. Essential fatty acids in health and chronic disease. Am. J. Clin. Nutr. 70, 560S-569S.

Souyert, H., Dardenne, P., Gillon, A., Croquet, C., Vanderick, S. \& Mayeres, P., Bertozzi, C. \& Gengler, N., 2006. Variation in fatty acid contents of milk and milk fat within and across breeds. J. Dairy Sci. 89, 4858-4865.

Stevenson, F.J. \& Cole, M. A., 1999. Cycles of soil: Carbon, nitrogen, phosphorus, sulfur, micronutrients, 2nd ed. John Wiley \& Sons, New York. 
Vasta, V., Priolo, A., Scerra, M., Hallett, K.G., Wood, J.D. \& Doran, O., 2009. $\Delta^{9}$ desaturase protein expression and fatty acid composition of longissimus dorsi muscle in lambs fed green herbage or concentrate with or without added tannins. Meat Sci. 82, 357-364.

Vessby, B., Gustafsson, I.B., Tengblad, S. \& Berglund, L., 2013. Indices of fatty acid desaturase activity in healthy human subjects: effects of different types of dietary fat. Br. J. Nutr. 110, 871-879.

Wang, Q., Chen, Y.J., Yoo, J.S., Kim, H.J., Cho, J.H. \& Kim, I.H., 2008. Effects of supplemental humic substances on growth performance, blood characteristics and meat quality in finishing pigs. Livest. Sci. 117, 270-274.

Warren, H.E., Scollan, N.D., Nute, G.R., Hughes, S.I., Wood, J.D. \& Richardson, R.I., 2008. Effects of breed and a concentrate or grass silage diet on beef quality in cattle of 3 ages. II: Meat stability and flavour. Meat Sci, 78, 270278.

Wood, J.D., Nute, G.R., Richardson, R.I., Whittington, F.M., Southwood, O., Plastow, G., Mansbridge, R., da Costa, N. \& Chang, K.C., 2004. Effects of breed, diet and muscle on fat deposition and eating quality in pigs. Meat Sci. 67 , 651-667.

Xazela, N.M., Chimonyo, M., Muchenje, V. \& Marume, U., 2012. Effect of sunflower cake supplementation on meat quality of indigenous goat genotypes of South Africa. Meat Sci. 90, 204-208. 